\title{
Accelerated Corrosion Tests on Lapped Spliced Joints in Concrete
}

\author{
Sara Eltayeb-Onsa \\ saronsa93@gmail.com \\ Civil Engineering Department, Faculty of Engineering, University of Khartoum, Khartoum, Sudan
}

Amged O. Abdelatif

Amged.Abdelatif@uofk.edu

Civil Engineering Department, Faculty of Engineering, University of Khartoum, Khartoum, Sudan

\begin{abstract}
This paper presents a new test setup of experiments to investigate corrosion at lapped spliced joints using accelerated corrosion test. The experiments were carried out on two set of samples: cylinders and beam blocks. Corrosion current readings were recorded with time and samples monitored for cracking pattern during the test. The results show that the cracks appearance and severity depend mainly on the cover diameter ratio. Also, the paper shows how the corrosion cracks propagate at lapped splice joints in concrete. The comparison of the results with previous literature was satisfactory.
\end{abstract}

Keywords: Corrosion; Lapped spliced joints; Accelerated corrosion test; Cracks; Current time relationship

\section{INTRODUCTION}

\subsection{General}

Reinforced concrete structures in severe environments may experience an unacceptable loss in serviceability earlier than anticipated due to corrosion of their steel reinforcement. Corrosion leads to the deterioration of structures by causing a remarkable reduction at the cross sectional area of the reinforcing steel bars and by causing cracking and spalling of the concrete cover due to expansive forces from corrosion products, and hence leading to a loss of structural bond between the reinforcement and concrete (Shihata A, 2011). The main problem of deterioration of reinforced concrete due to corrosion is not the reduction of reinforcement strength, but rather that the corrosion products induce stresses within the concrete, and the concrete therefore cracks leading to weakening the bond and anchorage between concrete and reinforcement which directly impairs the durability and ultimate strength of concrete elements (Shihata A, 2011).

\subsection{Effect of Corrosion on Bond between Reinforcing Steel and Concrete:}

Corrosion can be considered as one of the main causes leading to the reduction of the bond and thus reduction of member strength. A number of researchers indicated that the loss of strength in a corroded reinforced concrete member can be due to three factors which are: 1) losses in the effective cross-sectional area of concrete member because of the cracks in the concrete cover developed due to corrosion; 2) losses in the mechanical performance of reinforcing steel bars due to the losses in their cross-sectional area; and 3) losses in the bond performance of concrete with reinforcements. "Studies made by Auyeeung confirmed that the loss of bond strength for unconfined reinforcement is much 
more critical than cross-section loss; that is, a low percent diameter loss could lead to $80 \%$ bond reduction. Auyeeung's study also showed that confinement provides excellent means to counteract the bond loss (Fang C., Lundgren K., Chen L., \& Zhu C, 2004).

\subsection{Corrosion at lapped spliced joints}

Limited studies similar on the corrosion of steel reinforcement at lapped spliced joints in concrete were found. Previous studies investigated the corrosion at lapped spliced joints either experimentally using the accelerated corrosion test, or by using a finite element (FE) modelling.

An experimental study conducted by (Shihata A. \& Soudki K., 2011) examined the effect of confinement provided by CFRP on the bond strength of corroded tension lap splices in concrete beams under static loading. An accelerated corrosion test on 9 beams at different corrosion level and different cover diameter (c/d) ratios was conducted. The results showed that the highest bond strength reduction occurs at a cover diameter ratio of 1.5 .

The finite element study by Abdelatif AO et al. presented a numerical study of the chloride induced corrosion process in lap splice joints in concrete (AbdelatifA. O., Ozbolt, J. \& Gambarelli S, 2018). The study was conducted using 3D chemo-hygro-thermomechanical FE model developed to simulate the corrosion of lapped spliced joint. The results obtained from the model were compared with the results obtained from Shihata experiment (Shihata A. \& Soudki K., 2011). The comparison showed that the model results indicate an acceptable similarity to the results obtained from the experimental tests. Figure 1 shows the cracks results obtained from the model in comparison with the actual cracks from the experiment.

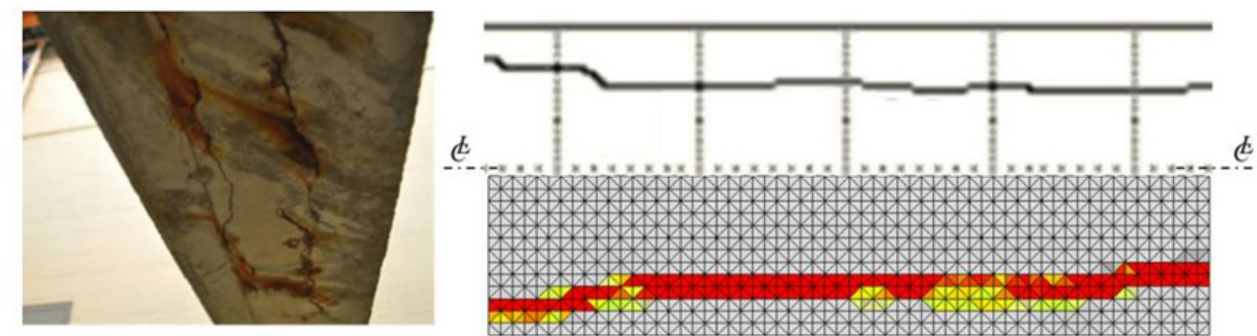

Figure 1: Cracks Pattern from the Model and from the Experiment (Abdelatif A. O., Ozbolt, J. \& Gambarelli S, 2018)

\section{EXPERIMENTAL PROCEDURE:}

The aim of the experimental work in this study is to achieve better understanding of corrosion at lapped spliced joints and the processes related to it. In this study two set of groups were tested, the first group consists of 4 cylinders with 2 steel bars embedded at their center, the second group consists of 2 blocks with reinforcement representing the lapped spliced joint zone on each beam.

\subsection{First group (Cylinders):}

All samples of this group have an average 28 days compressive strength of $24 \mathrm{MPa}$. 
A $10 \% \mathrm{NaCl}$ of cement weight was added to the mix to help accelerate the corrosion process. Table 1 shows the dimensions of the cylinders.

Table 1: Cylinder samples dimensions

\begin{tabular}{|l|l|l|l|l|}
\hline Sample ID & $\begin{array}{l}\text { Diameter of } \\
\text { rebar }(\mathrm{mm})\end{array}$ & $\begin{array}{l}\text { Added length in } \\
\text { the middle }(\mathrm{mm})\end{array}$ & Cover $(\mathrm{mm})$ & $\begin{array}{l}\text { Cover/Diameter } \\
\text { Ratio }(\mathrm{c} / \mathrm{d})\end{array}$ \\
\hline C-16-42 & 16 & 16 & 42 & 2.6 \\
\hline C-25-37.5 & 25 & 25 & 37.5 & 1.5 \\
\hline
\end{tabular}

\subsubsection{Accelerated Corrosion Test:}

In this study impressed voltage technique was used due to its simplicity to perform the test. The general layout of the test is shown in Figure 2. The first step of the sample preparation was wrapping the samples with stainless steel mesh to assure equal distribution of current around the cylinders. The test was started by applying a constant voltage of 12 volts to the system, after the test started current reading was taken twice a day using a digital multi-meter. Also the samples were checked about thrice a day to monitor the crack appearance and progression.

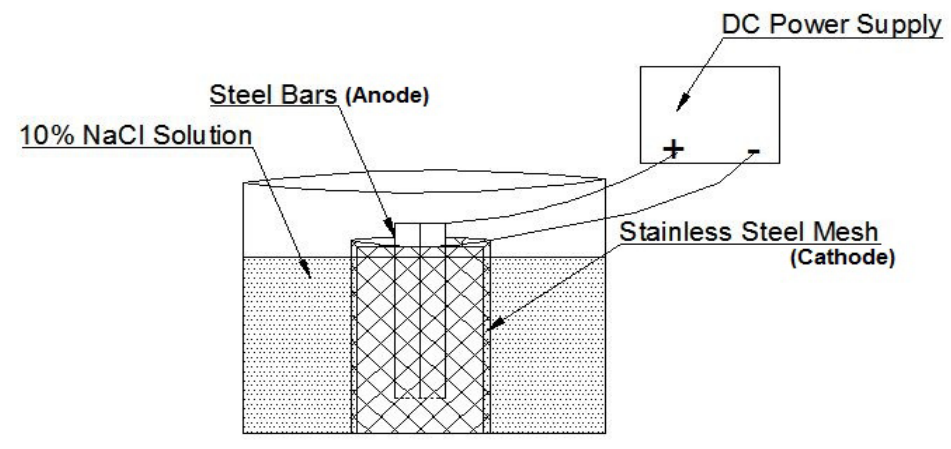

Figure 2: General Layout of the Test

\subsubsection{Test results of corrosion of lapped spliced joints in cylinder specimens:}

The results of the test show that all samples started to show cracks after short period of time but the development of crack was different for each sample according to its $\mathrm{c} / \mathrm{d}$ ratio. The test was continued until the crack became very sever. For each cylinder sample, both crack patterns (Figure 3) and time-current relationship (Figure 4) was presented.

(a) Cylinder C 16-42, c/d=2.6

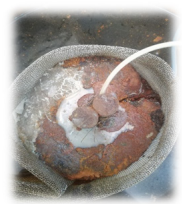

(b) Cylinder C 25-37.5, c/d = 1.5

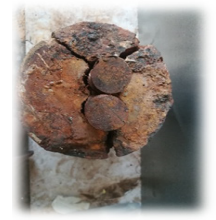

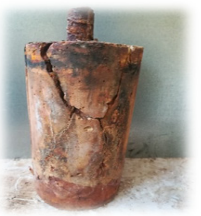

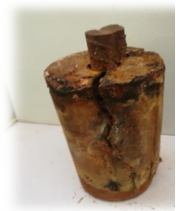

Figure 3: Crack pattern at lapped spliced joint in cylinder samples in: a) c/d = 2.6; b) c/d $=1.5$. 
The results show that the cracks were more developed in the cylinder C 25-37.5, c/d 1.5 compared to C 16-42, c/d 2.6. This could be due to the larger diameter and small cover. Also, it is noted that the first cylinder only shows longitudinal crack failure (Figure 4a) while in the second cylinder spalling of a concrete wedge is observed at the top (Figure $4 b$ ).

(a)

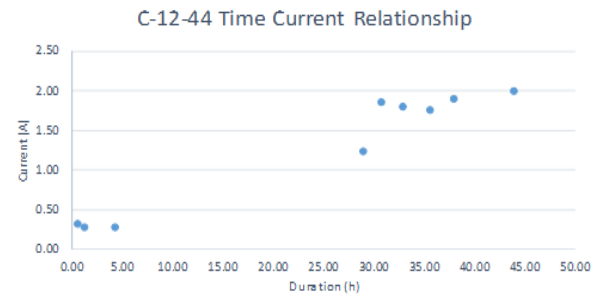

(b)

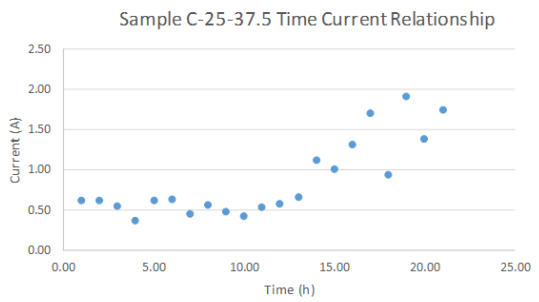

Figure 4: Time-current relationship at lapped spliced joint in cylinder samples in: a) c/d $=2.6 ; \mathrm{b}) \mathrm{c} / \mathrm{d}=1.5$.

\subsection{Second Group (Beams):}

The average 28 days strength of the block samples was $20 \mathrm{MPa}$. In these samples, a stainless-steel tube with diameter $10 \mathrm{~mm}$ was embedded in concrete as cathode. Steel bars diameters of $16 \mathrm{~mm}$ and $20 \mathrm{~mm}$ were used. The group consisted of 2 beam samples with dimension $(200 \times 200 \times 150) \mathrm{mm}$; each beam is reinforced with 4 steel bars at its bottom 2 at each end and equipped with a stainless steel tube with diameter $10 \mathrm{~mm}$ at the center as shown in Figure
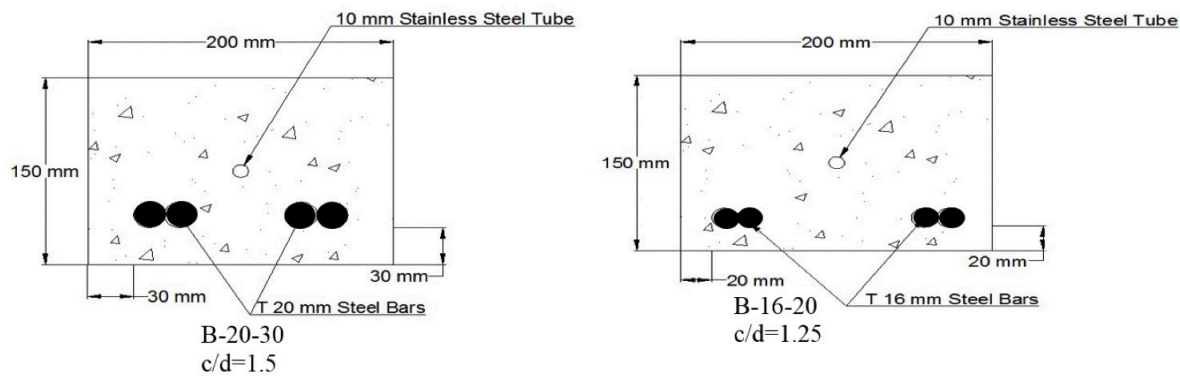

Figure 5: Beam specimens.

\subsubsection{Test setup of lapped spliced joints in beam specimens}

In this group, $10 \% \mathrm{NaCl}$ solution was sprinkled at the samples using a water pump connected with a hose with 2 sprinklers installed above the beams. figure shows the test setup. The test was started by applying constant voltage of 12 volts, the current readings were taken once or twice a day and the time and duration of the reading were also recorded. Moreover, the samples were visually inspected to monitor the cracks development. 

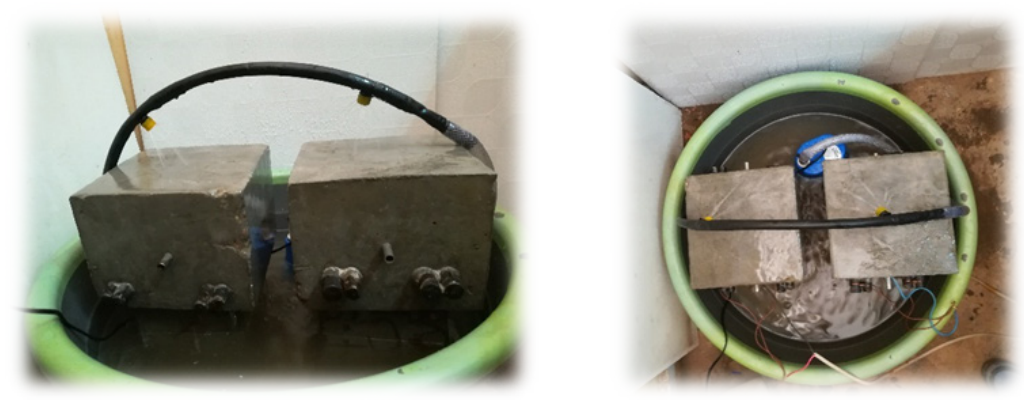

Figure 6: Test setup for beams group.

\subsubsection{Test results of corrosion of lapped spliced joints in beam specimens}

Both results of crack pattern and the relation of the corrosion current with time for these specimens were presented in Figure 7 and Figure 8. As an example, only the results for the beam block reinforced with $16 \mathrm{~mm}$ bars are presented.

Concrete cracks due to corrosion started to appear at different durations for each sample, the cracks were longitudinal and parallel to the steel bars. With time, the cracks became wider, and other cracks appeared between the bars and around the stainlesssteel tube, Figure 7. These findings were also observed in the experiment conducted by Shihata (Shihata A. \& Soudki K., 2011) as shown earlier in Figure 1 and similar to the finite element results by Abdelatif, AO et al. (Abdelatif A. O., Ozbolt, J. \& Gambarelli $\mathrm{S}, 2018$ ), The experiment was stopped after 544 hours of being subjected to the voltage.
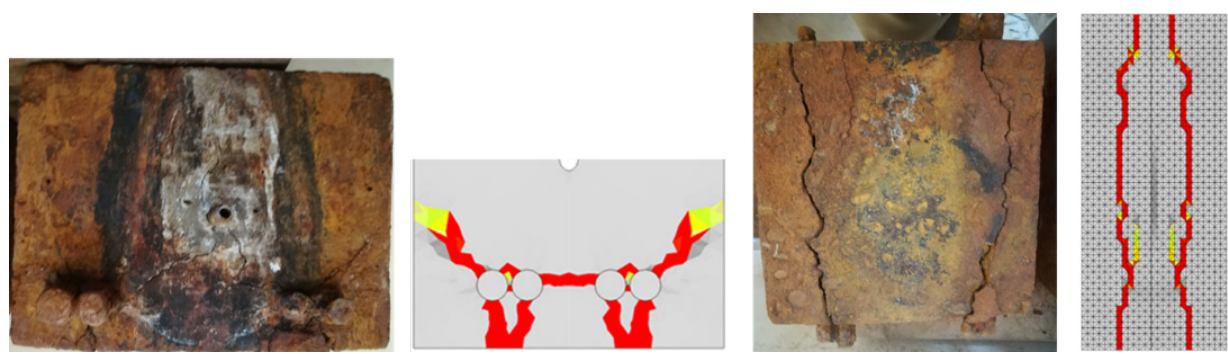

Figure 7: Crack pattern in a block specimen compared to previous FE results.

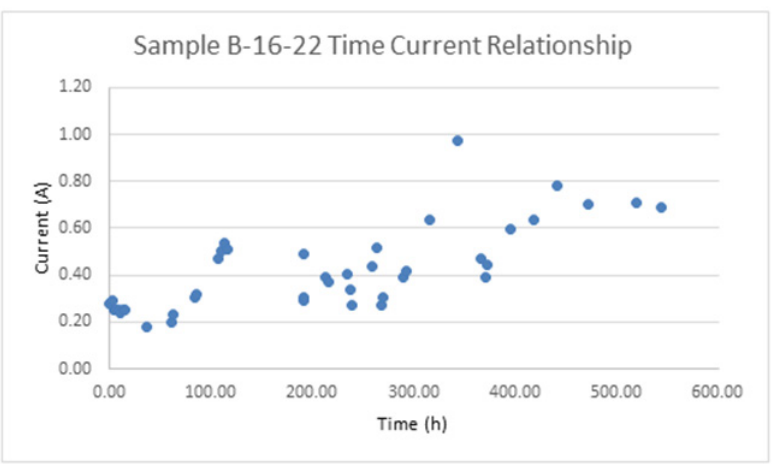

Figure 8: Time Current Relationship in a Block sample 
Time current relationship was plotted for each beam as shown in Figure 8. It is noted from the Time Current Relationship that the current reading increases significantly after the cracks appear; this happens due to the diminution of the concrete resistance to the voltage causing more current in the electrical circuit leading eventually for more and wider cracks.

\section{CONCLUSION}

This study developed an accelerated corrosion test to investigate the corrosion at lapped spliced joints in concrete. Both experimental results are matched with previous findings in the literature. The developed test was found to be able to study the corrosion at lapped splice joints and could be used in the future to bring more light on this topic.

For future studies in this field it is recommended to study the effect of corrosion of lapped spliced joints on the bond between the steel bars and the bond between the steel reinforcement and concrete utilizing both pull out test and finite element modelling.

\section{REFERENCES}

Abdelatif A. O., Ozbolt, J. \& Gambarelli S. (2018). 3D finite element modelling of corrosion of lap splice joints in concrete. Construction and Building Materials, 169, pp. 124-131.

Fang C., Lundgren K., Chen L. \& Zhu C. (2004). Corrosion influence on bond in reinforced concrete. Cement and Concrete Research, 34, pp. 2159-2167.

Shihata A. (2011). CFRP Strengthening of RC Beams with Corroded Lap Spliced Steel bars, Univercity of Waterloo.

Shihata A. \& Soudki K. (2011). Corroded Tension Lap-Spliced RC Beams with FRB Wraps, Waterloo, Canada. 